\title{
Evidencias de una educación accesible para todos y todas
}

\author{
Yorlenis Lilibeth García Soto ${ }^{1}$
}

\section{Información de artículo:}

Recibido: 30/09/2021

Aprobado: 15/12/2021

Palabras claves:

Educación Ambiental, Aulas

Interculturales, Deserción

Estudiantil, Psico-Afectiva

\section{Resumen}

La aparición del COVID-19 ha fragmentado el acceso a la educación, pero, es necesario establecer las rutas de aprendizajes para una educación ambiental, así como, promover procesos interculturales en las aulas de clases que coadyuven a desarrollar la faceta psico-afectiva y cognitiva en los estudiantes y disminuir la deserción estudiantil.

\section{Keywords:}

Environmental Education, Intercultural Classrooms, Student Dropout, Psycho-Affective

\section{Evidence of an accessible education for all}

\section{Abstract}

The appearance of COVID-19 has fragmented access to education, but it is necessary to establish learning routes for environmental education, as well as promote intercultural processes in classrooms that help develop the psycho-affective and cognitive facet. in students and reduce student desertion.

\footnotetext{
${ }^{1}$ Ingeniera en Zootecnia. Editora de la Revista Electrónica de Conocimientos, Saberes y Prácticas. Email: liliyorkgs@gmail. com (D): https://orcid.org/0000-0002-5590-4504
} 


\section{Justificación del monográfico}

La educación es un derecho humano que se sustenta en el ODS 4, garantizar una educación inclusiva, equitativa y de calidad y promover oportunidades de aprendizaje durante toda la vida para todos. Además, en la Declaración de Incheon se establecen principios como: (1) la educación es un derecho humano fundamental y un derecho habilitador; (2) la educación es un bien público; y (3) la igualdad de género (UNESCO, 2015, p. 7). Lo que significa que la educación tiene que ser accesible para todos y todas. La educación ayuda a las personas a aprovechar todo su potencial mediante el desarrollo de valores y la adquisición de conocimientos fundamentales para participar de manera eficaz en el mundo labora y la vida, y crear sociedades mejores (UNESCO, 2021, p. 5).

La aparición del COVID-19 ha fragmentada el acceso a la educación. El acceso significa crear las mismas condiciones y oportunidades para todos y todas, independientemente de las personas o grupos al que pertenezcan, sin embargo, el COVID-19 ha contribuido a incrementar las brechas de acceso a la educación. Por ejemplo, en este contexto de la pandemia, las mujeres tienen menos posibilidades de utilizarlas tecnologías de la información y comunicación para fines básicos, y mucho menos para fines informáticos o de codificación (UNESCO, 2021, p. 4).

Por lo anterior, es necesario avanzar en metodologías disruptivas tales como: aprendizaje personalizado; aprendizaje entre pares; aprendizaje basado en problemas; aprendizaje basado en la investigación; aprendizaje colaborativo internacional en línea (Flores-López, 2021). Además, establecer las rutas de aprendizajes para una educación ambiental, así como, promover procesos interculturales en las aulas de clases que coadyuven a desarrollar la faceta afectiva en los estudiantes y disminuir la deserción estudiantil (García-Soto, 2021).

\section{Estructura y presentación del monográfico}

La Revista Electrónica de Conocimientos, Saberes y Prácticas trata de evidenciar las investigaciones que relatan una educación para todos y todas siguientes:

En la investigación de Cardona-Castaña et al. (2021) se estudian las percepciones de algunos adolescentes sobre el ambiente, es factor esencial dentro de la comprensión hombre - naturaleza. La actual pandemia producida por el COVID-19, permitió que los sujetos, pudieren observar su entorno con detenimiento, conduciendo a cambios en las percepciones. Todo ello, se construyó desde la educación ambiental; herramienta que sirvió para explorar y sentir los beneficios del espacio, todo ello durante el confinamiento. El objetivo de la investigación, consistió en analizar e interpretar las percepciones que tienen un grupo de adolescentes, en situación de vulnerabilidad frente al entorno en tiempos de confinamiento por la pandemia COVID-19. Los procesos urbanos y el ruido de la ciudad no permiten develar la importancia de la 


\section{EDITORIAL}

naturaleza. No obstante, el ambiente como una estructura inquebrantable ante la realidad humana, el silencio que produjo la pandemia condujo al grupo de estudio a nuevas experiencias dentro del espacio que habitan, por ejemplo: sonidos, observación de nuevas aves, insectos, etc. En finalidad, los participantes reflexionaron sobre los cambios que trajo el confinamiento y el significado del ambiente estrechando la relación con la naturaleza. También, el crecimiento de la ciudad trae perturbaciones en la naturaleza, cambiando el paisaje.

En Solís-Narváez et al. (2021) se presenta un acercamiento a los estudiantes de Mayangnas en relación a los retos de la educación superior tanto académicos como culturales y la necesidad de redimensionar la práctica educativa de enseñanza - aprendizaje en pro del reconocimiento socio-histórico, y cultural del aula como espacio intercultural. El texto representa un acercamiento a la producción de espacios interculturales desde la óptica de los sujetos de investigación, que podría brindar luces de cara a los procesos de transformación académica, pero, sobre todo, al tratamiento pertinente a estudiantes de orígenes étnicos.

Así mismo, Chow-White y Flores-López (2021) analizaron los factores de deserción estudiantil en un contexto universitario. Las variables de análisis fueron: edad, género, etnia, estado civil, laboral, número de hermanos, números de hijos, lugar de procedencia, estudio (secundaria), tipo carrera y el semestre que abandono la carrera. Los principales resultados muestran que la investigación el índice de deserción fue de $34 \%$ y los principales factores que incidieron en la deserción estudiantil universitaria fue de orden económico, entorno familiar, antecedentes académicos, factor motivacional, autoestima, vocacional y el académico institucional; pese a la deserción ocurrida del $47 \%$ de los desertores logró alcanzar bases académicas y un título técnico universitario, lo cual los hace competitivos en el mercado laboral.

En Suárez y Obando-Téllez (2021) sistematizaron una intervención físico - psico - afectivo en el adulto mayor desarrollada por los estudiantes de enfermería. En el trayecto de la intervención se manifestaron aspectos interesantes, tales como: fortalecimiento de la acción extensionista de la Universidad, reconocimiento social, desarrollo de capacidades resolutivas y humanísticas por parte de los estudiantes pero también innovación y creatividad de la práctica docente. La información utilizada fue obtenida mediante una base de datos establecida por los estudiantes por cada cohorte la que sirvió como evidencia para demostrar que la estrategia ha sido generadora de impacto social pero también enriquecedor de una actividad extensionista, creativa e innovadora.

Y finalmente, Zúniga-Morales y Flores-López, realizan una revisión bibliográfica con el objetivo de analizar la evolución y modelos teóricos referentes del emprendimiento obteniendo como resultados que el emprendimiento: ha tenido un gran desarrollo expresadas evolutivo; no existe una única teoría; sobresaliendo el modelo 
teórico de la conducta planificada, concluyendo que el emprendimiento como la innovación son conceptos polisémicos, sin embargo, el emprendimiento innovador es cuando ambos procesos confluyen.

\section{Lista de referencias}

Cardona-Castaño, J. C., Lamprea-Zona, M. C., \& Cubides-Suárez, F. A. (2021). Significados y percepciones del ambiente por adolescentes: Reflexión en tiempos de pandemia. Revista Electrónica De Conocimientos, Saberes Y Prácticas, 4(2), 9-24.https://doi.org/10.5377/recsp.v4i2.13385

Chow-White, V. E., \& Flores-López, W. O. (2021). Deserción estudiantil universitaria: Un estudio en una Universitaria Comunitaria Intercultural. Revista Electrónica De Conocimientos, Saberes Y Prácticas, 4(2), 43-67. https://doi.org/10.5377/ recsp.v4i2.13387

Flores-López, W. O. (2021). Actitudes y creencias para la disrupción de la educación en contexto del COVID-19. Revista Electrónica De Conocimientos, Saberes Y Prácticas, 4(1), 5-12. https://doi.org/10.5377/recsp.v4i1.12091

García-Soto, Y. L. (2021). Evidencias de una educación accesible para todos y todas. Revista Electrónica De Conocimientos, Saberes Y Prácticas, 4(2), 5-8. https://doi. org/10.5377/recsp.v4i2.13384

Solis-Narváez, N. S., Lane, P. M., \& Gómez-Salazar, E. A. (2021). Aulas Interculturales: Perspectiva de la educación de los estudiantes Mayangnas Intercultural Classrooms: Perspective of the education of Mayangnas students. Revista Electrónica De Conocimientos, Saberes Y Prácticas, 4(2), 25-42. https://doi. org/10.5377/recsp.v4i2.13386

Suárez, Z. A., \& Obando-Téllez, P. J. (2021). Sistematización de una estrategia metodológica: intervención físico - psico-afectivo en el adulto mayor desarrollada por los estudiantes de enfermería, cohorte 2018 - 2020. Revista Electrónica De Conocimientos, Saberes Y Prácticas, 4(2), 68-82. https://doi.org/10.5377/recsp. v4i2.13388

UNESCO. (2015). Declaración de Incheon. Educación 2030. Hacia una educación inclusiva y equitativa de calidad y un aprendizaje a lo largo de la vida para todos. UNESCO. https://hdl.handle.net/20.500.12365/18066

UNESCO. (2021). Nota conceptual del informe de seguimiento de la educación en el mundo 2023 sobre tecnología y educación. UNESCO. https://bit.ly/3ugrOYx 
Zúniga-Morales, V. R., \& Flores-López, W. O. (2021). El emprendimiento innovador: una aproximación epistémica, práctica e investigativa de su evolución históricateórica. Revista Electrónica De Conocimientos, Saberes y Prácticas, 4(2), 83-96. https://doi.org/10.5377/recsp.v4i2.13389 